\title{
Canadian Public Health Laboratory Network laboratory guidelines for the use of serological tests (excluding point-of-care tests) for the diagnosis of syphilis in Canada
}

\author{
Paul N Levett DSc (D)ABMM FCCM FAAM ${ }^{1}$, Kevin Fonseca PhD D(ABMM) ${ }^{2}$, Raymond SW Tsang PhD ${ }^{3}$, \\ Kamran Kadkhoda PhD FCCM ${ }^{4}, 5$, Bouchra Serhir MSc PhD ${ }^{6}$, Sandra M Radons BSc ${ }^{7}$, Muhammad Morshed PhD SCCM ${ }^{8,9^{*}}$
}

PN Levett, K Fonseca, RSW Tsang, et al. Canadian Public Health Laboratory Network laboratory guidelines for the use of serological tests (excluding point-of-care tests) for the diagnosis of syphilis in Canada. Can J Infect Dis Mid Microbiol 2015;26(Suppl A):6A-12A.

Syphilis, caused by the bacterium Treponema pallidum subsp. pallidum, is an infection recognized since antiquity. It was first reported at the end of the 15th century in Europe. Infections may be sexually transmitted as well as spread from an infected mother to her fetus or through blood transfusions. The laboratory diagnosis of syphilis infection is complex. Because this organism cannot be cultured, serology is used as the principal diagnostic method. Some of the issues related to serological diagnoses are that antibodies take time to appear after infection, and serology screening tests require several secondary confirmatory tests that can produce complex results needing interpretation by experts in the field. Traditionally, syphilis screening was performed using either rapid plasma reagin or Venereal Disease Research Laboratory tests, and confirmed by treponemal tests such as MHA-TP, TPPA or FTA-Abs. Currently, that trend is reversed, ie, most of the laboratories in Canada now screen for syphilis using treponemal enzyme immunoassays and confirm the status of infection using rapid plasma reagin or Venereal Disease Research Laboratory tests; this approach is often referred to as the reverse algorithm. This chapter reviews guidelines for specimen types and sample collection, treponemal and non-treponemal tests utilized in Canada, the current status of serological tests for syphilis in Canada, the complexity of serological diagnosis of syphilis infection and serological testing algorithms. Both traditional and reverse sequence algorithms are recommended and the algorithm used should be based on a combination of local disease epidemiology, test volumes, performance of the proposed assays and available resources.

Key Words: Enzyme immunoassay; Reverse algorithm; RPR; Serological diagnosis; Syphilis; Treponema pallidum
Les directives du Réseau des laboratoires de santé publique du Canada sur l'utilisation des tests sérologiques (à l'exception des tests au point de service) pour diagnostiquer la syphilis au Canada

La syphilis, causée par la bactérie Treponema pallidum sous-espèce pallidum, est une infection connue depuis l'antiquité. Elle a été signalée pour la première fois en Europe, à la fin du $\mathrm{XV}^{\mathrm{e}}$ siècle. Les infections peuvent être transmises sexuellement, par une mère infectée à son foetus ou par des transfusions sanguines. Il est difficile de diagnostiquer la syphilis en laboratoire. Puisque cet organisme ne peut pas être mis en culture, la sérologie est la principale méthode diagnostique. Parmi les problèmes liés aux diagnostics sérologiques, soulignons qu'il faut du temps pour que les anticorps fassent leur apparition après l'infection et que les tests de dépistage sérologique doivent s'associer à plusieurs tests de confirmation secondaires qui peuvent produire des résultats complexes devant être interprétés par des experts dans le domaine. Habituellement, la syphilis était dépistée au moyen du test rapide de la réagine plasmatique ou du test Veneral Disease Research Laboratory et était confirmée par les tests tréponémiques comme le MHA-TP, le TP-PA ou le FTA-Abs. Cette tendance s'inverse actuellement, car la plupart des laboratoires du Canada dépistent la syphilis au moyen d'épreuves immunoenzymatiques tréponémiques et confirment le statut de l'infection au moyen du test rapide de la réagine plasmatique ou du test Veneral Disease Reseach Laboratory. Cette approche est souvent désignée par le terme algorithme inversé. Ce chapitre analyse les directives sur les types de prélèvements et la collecte des échantillons, les tests tréponémiques et non tréponémiques utilisés au Canada, le statut actuel des tests sérologiques de la syphilis au Canada, la complexité du diagnostic sérologique d'infection par la syphilis et les algorithmes des tests sérologiques. Tant l'algorithme habituel que l'algorithme inversé sont recommandés, et l'algorithme utilisé devrait tenir compte à la fois de l'épidémiologie locale de la maladie, du volume de tests, de l'exécution des tests proposés et des ressources disponibles.

licensing status for diagnostic testing by Health Canada. These include one Veneral Disease Research Laboratory (VDRL) test and one rapid plasma reagin (RPR) product.

A larger number of treponemal antibody assays have been licensed. Several EIA/CIA assays were licensed, some capable of detecting immunoglobulin (Ig) G antibodies only and others capable of detecting both IgG and IgM antibodies. In addition, there are four immunoassays licensed for
There is no single serological test that can be performed on a single blood specimen that can tell you if that patient has active syphilis or not.

Serological tests are divided into those which detect non-treponemal antibodies (or reagins) and those which detect treponemal antibodies. Currently only two non-treponemal antibody assays have updated their

${ }^{1}$ Saskatchewan Disease Control Laboratory, Regina, Saskatchewan; ${ }^{2}$ Alberta Provincial Laboratory for Public Health, Calgary, Alberta; ${ }^{3}$ National Microbiology Laboratory; ${ }^{4}$ Cadham Provincial Laboratory; ${ }^{5}$ Department of Medical Microbiology $\mathbb{E}$ Infectious Diseases and Department of Immunology, University of Manitoba, Winnipeg, Manitoba; ${ }^{6}$ Institut national de santé publique du Quebec-LSPQ, Sainte-Anne-de-Bellevue, Quebec; ${ }^{7}$ Canadian Public Health Laboratory Network, Winnipeg, Manitoba; ${ }^{8}$ BC Public Health Microbiology and Reference Laboratory;

${ }^{9}$ Department of Pathology and Laboratory Medicine, University of British Columbia, Vancouver, British Columbia.

*Denotes section lead

Correspondence: Dr Muhammad Morshed, BC Public Health Microbiology and Reference Laboratory, 655 West 12th Avenue, Vancouver, British Columbia V5Z 4R4. Telephone 604-707-2622, fax 604-707-2602, e-mail muhammad.morshed@bccdc.ca 
use on automated analyzers. A single fluorescent treponemal antibodyabsorption (FTA-ABS) assay and a single Trepoenma pallidum particle agglutination (TP-PA) assay have been licensed for use in Canada.

The confirmation of infection with syphilis is often based on the presence of syphilis-specific antibody in a serum or plasma sample detected by treponemal assays. However, a positive treponemal test result does not differentiate between active and past infections. A person with active infection may have both non-treponemal reagins and treponemal antibodies in the blood, while patients with adequately treated past infection may still have a positive treponemal test result but their non-treponemal test findings will be negative or low titre (1:1 or $1: 2)$. Traditionally, patients with suspected syphilis are screened with a non-treponemal test and any positive results are confirmed by a treponemal test. However, with the advent of newer automated treponemal tests, some laboratories have modified their diagnostic algorithm to a reverse algorithm of screening with a treponemal test (1). This change in diagnostic algorithms for the serological diagnosis of syphilis has created challenges that will be discussed in the present review, together with an overview of the types of treponemal and non-treponemal tests commonly employed in the diagnostic laboratories in Canada. Based on a literature review of the common current practice and the experience of the Canadian Public Health Laboratory Network's (CPHLN) national task group on laboratory diagnosis of syphilis, suggested guidelines on how to follow the two diagnostic algorithms have been developed and the pros and cons of each algorithm will be discussed in this section.

\section{GUIDELINES FOR SPECIMEN TYPES AND SAMPLE COLLECTION}

In the early 1960s, plasma was the sample of choice as screening tests for syphilis were designed to be performed in the field, without access to laboratory equipment (2). However, the poor specificity of this assay and development of better screening assays have resulted in serum being used almost exclusively. Venous blood should be allowed to clot adequately in a clean tube without anti-coagulant before the serum is separated and removed because samples not completely clotted may contain fibrinogen or fibrin strands that may interfere with the assays, especially those based on flocculation (3).

Cord blood, once regarded as a useful sample for the detection of congenital syphilis, is now considered a suboptimal specimen type. Wharton's jelly, comprised of mucopolysaccharides, is found in the umbilical cord and can cause false-positive non-treponemal results (4). The issue associated with cord blood, which applies to all serological tests, is the possibility of contamination with the maternal blood, which is, by far, a more probable source of false positivity.

\section{TYPES OF SEROLOGICAL TESTS}

\section{Non-treponemal tests}

Non-treponemal tests detect antibodies (reagins) that react with lipoidal particles containing cardiolipin (5). Historically, the antigen was obtained by Wasserman from the liver of an infant who had died of congenital syphilis, and used in the complement fixation test. However, it was quickly realized that the antibodies were crossreactive and an alcohol extract from bovine heart was equally suitable for this purpose (6). The identification of the phospholipid cardiolipin as the active antigenic component led to the development of standardized antigens containing cardiolipin, cholesterol and lecithin $(7,8)$.

The VDRL test (8) is a flocculation test developed using the standardized antigen preparation, and remains in use today. The antigen was further modified by the addition of chlorine chloride and EDTA to produce the unheated serum regain test (USR), in which either plasma or unheated serum was an acceptable sample matrix (9).

Other non-treponemal tests were developed, including the RPR test and the toluidine red unheated serum test (TRUST). In the RPR test, the antigen suspension incorporates charcoal particles to enhance flocculation (10), while in the TRUST the carbon particles were replaced with toluidine red particles (11).
All non-treponemal tests have similar performance characteristics. They detect both IgM and IgG antibodies (Figure 1). The sensitivity of non-treponemal tests during primary syphilis is approximately $75 \%$ (12). All non-treponemal tests in current use are flocculation tests, in which the reaction between the antigen and reagin is evidenced by clumping of particles. Interpretation of flocculation tests is subjective and, therefore, depends on staff experience, with a minimum of \pm 1 dilution margin of error associated with these types of tests.

The non-treponemal tests currently licensed and available in Canada are the RPR and the VDRL. The VDRL is now used primarily for testing CSF (6).

Non-treponemal tests are used as qualitative assays for screening in the traditional algorithm or as quantitative assays to assess the response to treatment. Screening tests are performed using undiluted serum. Results are reported as non-reactive or reactive. Some specimens give a granular or 'rough' appearance. A prozone phenomenon occurs in high-titre specimens, which appear as non-reactive unless the samples are diluted (13). Reactive specimens are re-tested in a two-fold dilution series for quantitative results. Titres usually decline significantly after successful therapy (14). Treated patients should be followed for up to 24 months (15); this prolonged follow-up is necessary to ensure titres decline to the expected extent.

False-positive reactions occur with non-treponemal tests (16). These are categorized as either acute (occurring for $<6$ months) or chronic. The recognized causes of acute false-positive reactions include other febrile illnesses, immunizations and pregnancy (17). Patients with acute false-positive reactions should be re-tested in three to six months. Chronic false-positive reactions are associated with hepatitis $\mathrm{C}$ infection (1), connective tissue diseases, intravenous drug use, malignancy, older age, malaria, Chagas disease, tuberculosis and leprosy (6).

\section{Treponemal tests}

The first treponemal tests were developed $>60$ years ago, using either live or killed cells of the Nichols strain of T. pallidum $(6,18)$. Treponemal tests detect both IgM and IgG antibodies. The antibodies detected by treponemal assays appear up to a few weeks earlier than those detected by non-treponemal tests.

The tests that remain available today include the T. pallidum hemagglutination assay (TPHA), the T. pallidum particle agglutination assay (TPPA), and the FTA-ABS $(19,20)$. These early treponemal assays utilized whole cells, or antigens derived from cells of T. pallidum.

The FTA-ABS is an indirect immunfluorescent staining assay, in which fixed cells of the Nichols strain of T. pallidum are exposed to the test serum after they have been absorbed with a sorbent, which is an extract from a non-pathogenic $T$. phagedenis strain sometimes referred to as the Reiter strain. After washing to remove unbound antibody, the reaction mixtures are incubated with fluorescein-conjugated anti-human globulin. In a positive test, the presence of antibodies to T. pallidum in the serum specimen is indicated by the appearance of fluorescent spirochetes when viewed with a fluorescence microscope. The FTA-ABS is slightly more sensitive than either the TPHA or the TPPA, and is usually the first serological test to become reactive, during the primary stage of the disease (6). However, the FTA-ABS is subjective and occasionally gives false-positive (non-specific fluorescence) readings.

The TPHA and TPPA are indirect agglutination tests in which surface antigens extracted from T. pallidum cells are coated onto red cells (TPHA) or gelatin particles (TPPA) and mixed with the test serum. Serum containing specific T. pallidum antibodies will react with the antigen-sensitized red cells or particles, causing agglutination.

In recent years, new treponemal tests have been developed that utilize recombinant antigens derived from T. pallidum. This approach may allow greater specificity and sensitivity and also promotes standardization (see Table 1 for a list of recombinant treponemal tests available in Canada).

Recombinant treponemal assays suitable for screening are available in EIA/CIA format (for IgG, for IgM, and for total immunoglobulins), in chemiluminescence assay format and in a multiplex bead immunoassay format. Table 1 shows the available assays. 
The chemiluminescence and multiplex bead immunoassays are capable of high throughput and even random-access testing, but each is only capable of running on the manufacturer's platform. Limited data suggest that the performance of these assays for screening is very similar (21-23).

Accumulating anecdotal experience with treponemal assays as screening tests suggests that these assays generate a small proportion of positive results, which cannot be explained by previous infections. Because these tests have not been applied as tests for screening populations before, it should not be a surprise that apparently false-positive results occur in a small proportion of the population. Among the causes of false-positive treponemal tests are other spirochetal infections, such as borrelial infections, in addition to the causes of falsepositive results in non-trepnemal tests. Further studies will be necessary to quantify the rate of false-positive results, although considering their higher analytical sensitivity and also in the absence of a gold standard, it is difficult to prove that the results obtained using these new platforms are necessarily false positive, hence demanding a thorough search into the patient's medical and social history, and to perform risk assessment by the health care provider.

A number of immunoblot assays are available, but none are currently licensed by Health Canada. A potential application of these assays is to reconcile discordant results because they allow the users to visualize the reacting antigens (24-26).

\section{ALGORITHMS FOR SEROLOGICAL DIAGNOSIS}

Currently there are two commonly used approaches to the serological diagnosis of syphilis. In the traditional algorithm (Figure 2), a reactive nontreponemal screening test is followed by a treponemal confirmatory assay.

The second algorithm - commonly referred to as a reverse sequence algorithm (Figure 3) - utilizes a treponemal test for screening (27) and, in most cases, is followed by a quantitative non-treponemal test. This algorithm presents several potential advantages, which include the elimination of biological false-positive results in non-treponemal tests and the possibility of detecting antibodies earlier in the course of primary syphilis than would be the case if a non-treponemal screening test were used as well as in some RPR-negative latent syphilis patients. Both algorithms require the titration of reactive sera using RPR and VDRL, in order to help with disease staging, assess response to treatment and to help determine if re-infection has occurred (28).

A variation of the reverse sequence algorithm is recommended by the European Centre for Disease Prevention and Control (ECDC): a reactive treponemal screening test is followed by a second treponemal test but is not accompanied by a non-treponemal test (29) This latter version of the reverse sequence algorithm is not currently in use in Canada.

Adoption of the second algorithm will produce some cases with positive treponemal and negative RPR tests $(30,31)$, which will need to be managed appropriately. A small proportion $(<1 \%)$ of normal sera may be reactive in treponemal tests $(6,16)$. While this proportion is very small, it may translate to a large number of individual patients when treponemal tests are used for screening instead of being used to confirm a reactive nontreponemal test. A recent report suggested that sera with discordant results should be tested with a second treponemal test (32), preferably with equal or higher sensitivity than the primary treponemal test (33). Some have expressed the opinion that samples that have been screened positive by a treponemal test but are negative by non-treponemal test and a second treponemal test likely represent false positives and syphilis is unlikely (34). However, more recent studies have argued that caution should be taken before discarding these isolated EIA or CIA results as false positives because they may occur in high-risk individuals with early or latent syphilis, and some have been shown to seroconvert upon follow-up examination $(35,36)$. In such situations, it is prudent to repeat the serological tests two to four weeks after the initial test to ensure that the patient does not have early primary syphilis.

A recent analysis suggested that whether the algorithm used employed a treponemal assay followed by a non-treponemal assay, or alternatively a non-treponemal assay followed by a treponemal assay, the outcome in case numbers detected or adverse outcomes prevented would be the same (37). In addition, there were similar outcomes in terms of overtreatment rates. A recent Canadian study, however, demonstrated an increase in late latent cases of syphilis that required additional public health follow-up (38). The use of treponemal tests for screening, followed by non-treponemal tests, also resulted in higher overall testing costs (37). Tong et al (39) conducted a cross-sectional study of three syphilis testing algorithms: traditional algorithm, reverse algorithm, and the European Centre for Disease Prevention and Control (ECDC) algorithm and reported that the traditional algorithm had the highest negative likelihood ratio (0.24), a missed diagnosis rate of $24.2 \%$, and only $75.81 \%$ sensitivity. However, both the reverse and ECDC algorithms had higher diagnostic efficacy than the traditional algorithm with reported sensitivity, specificity, and accuracy of $99.38 \%$ to $99.85 \%, 99.98 \%$ to $100.00 \%$ and $99.93 \%$ to $99.96 \%$, respectively. While their study supported the use of the ECDC algorithm, in which syphilis screening begins with a treponemal immunoassay that is followed by a second, different treponemal assay as a confirmatory test in high-prevalence populations, they acknowledged that a non-treponemal assay is recommended for determining serological activity and the effect of syphilis treatment.

The decision to use a treponemal or non-treponemal assay as the first screening test in the diagnostic algorithm should be based on local syphilis epidemiology, the expected workload, the requirement for automation and the available budget for labour and consumables (40).

\section{CURRENT STATUS OF SEROLOGICAL TESTS FOR SYPHILIS IN CANADA}

Serological testing for syphilis diagnosis in Canada was surveyed recently (41). Serological testing is performed in all public health laboratories in each of the provinces, and in many regional, hospital and/or private laboratories in New Brunswick, Nova Scotia, Newfoundland and Labrador, Prince Edward Island, Quebec and Alberta. Diagnostic testing in the territories varies, with most of the territories relying on used other provincial laboratories for either primary and/or confirmatory testings, except Nunavut, where RPR screening is performed. In some provinces, syphilis serology testing is centralized at the provincial public health laboratory, while in other provinces, eg, Quebec, there were $>80$ laboratories providing the initial screening test.

Syphilis test algorithms varied significantly in provinces and territories. Both non-treponemal and treponemal tests are performed for screening tests (Figures 1 and 2) (41) and a wide range of commercial products are used for non-treponemal and treponemal testing. Although line immunoassay (LIA) has not been approved for use as medical device by the Therapeutic Products Directorate of Health Canada, a few laboratories are using this test for the discrepant samples, under special access licenses from the Therapeutic Products Directorate (42).

\section{RECOMMENDED ALGORITHMS: TREPONEMAL AND NON-TREPONEMAL}

After reviewing the current data on syphilis serological testing and group discussion, the CPHLN Syphilis Laboratory Task Group came to the conclusion that both the traditional algorithm (screening by a non-treponemal assay followed by a treponemal assay) and the reverse algorithm (screening by a treponemal assay followed by a nontreponemal assay) are appropriate, and that decisions to implement a diagnostic algorithm should be based on local syphilis epidemiology and other considerations, including expected workload, need for automation and budget considerations.

The traditional algorithm performs well in identifying persons with active infection, while minimizing false-positive results in lowprevalence populations. If the reverse sequence algorithm is used, CPHLN Syphilis Laboratory Task Group recommends that a specimen with reactive EIA/CIA results be tested reflexively with a quantitative nontreponemal test (eg, RPR or VDRL) as well as TPPA to reduce falsepositive cases (Figure 3). In high-test-volume laboratories, discordant 


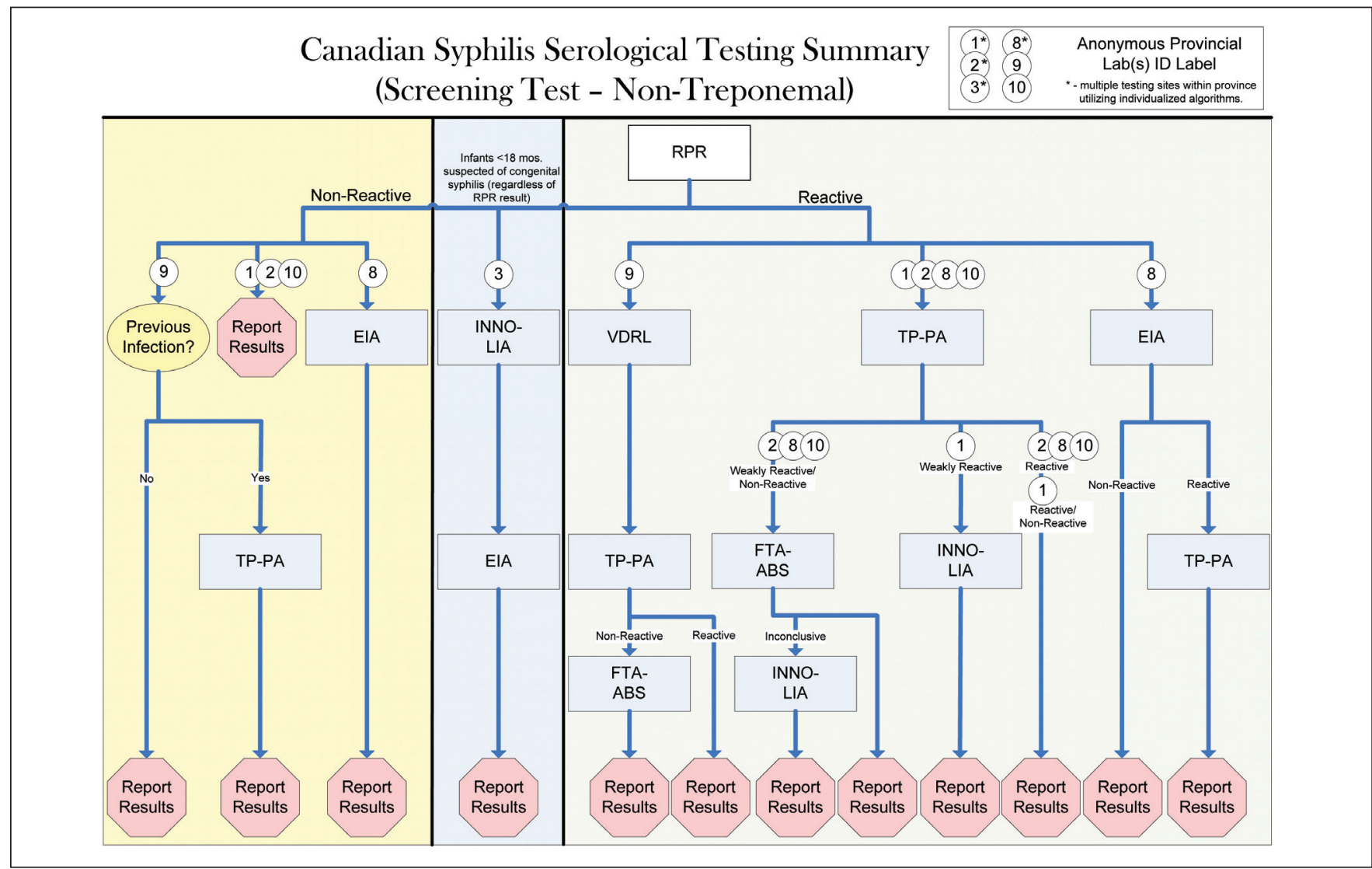

Figure 1) 2009 Canadian syphilis survey serological testing summary for non-treponemal screening (41).

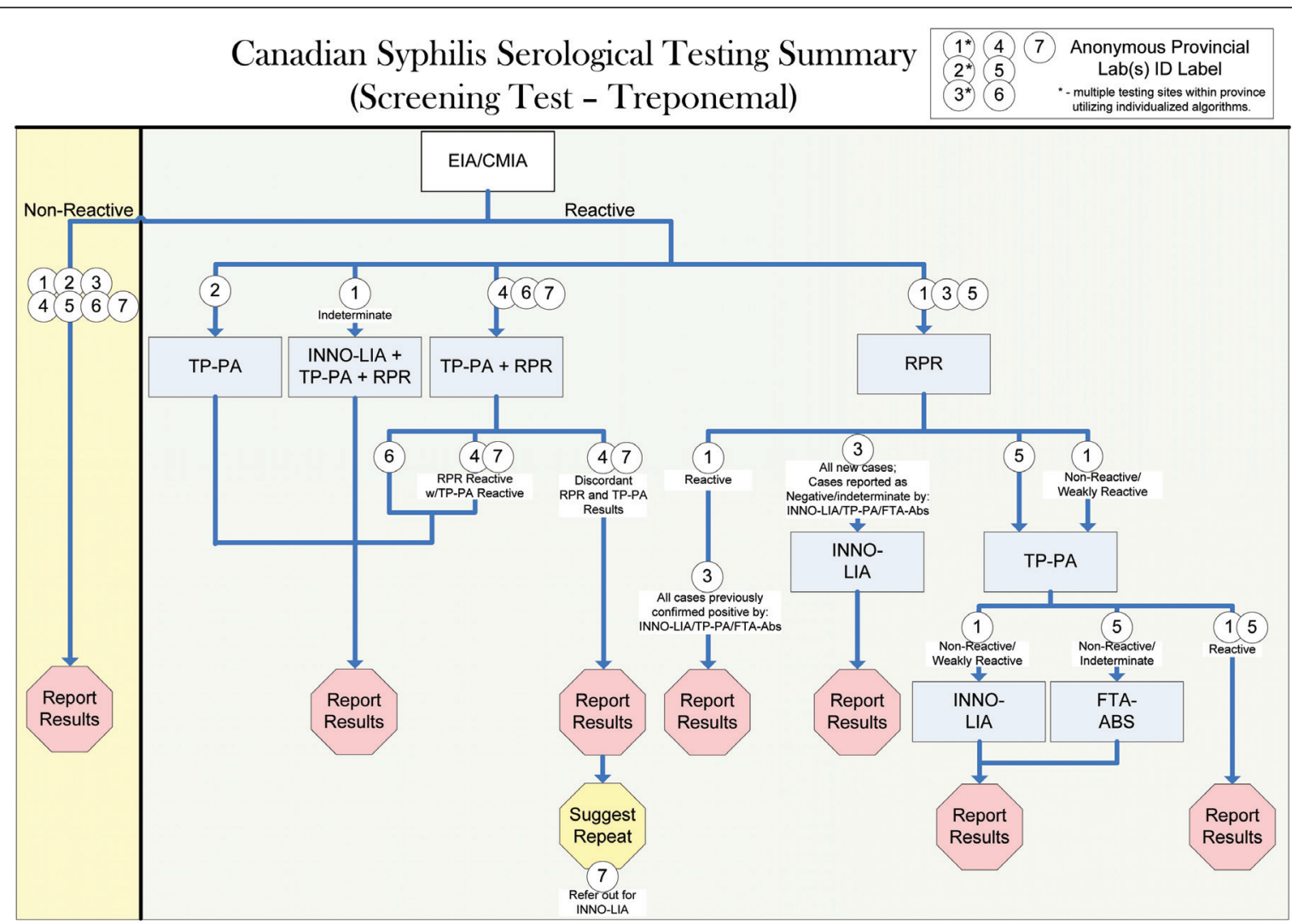

Figure 2) 2009 Canadian syphilis survey serological testing summary for treponemal screening (41) 


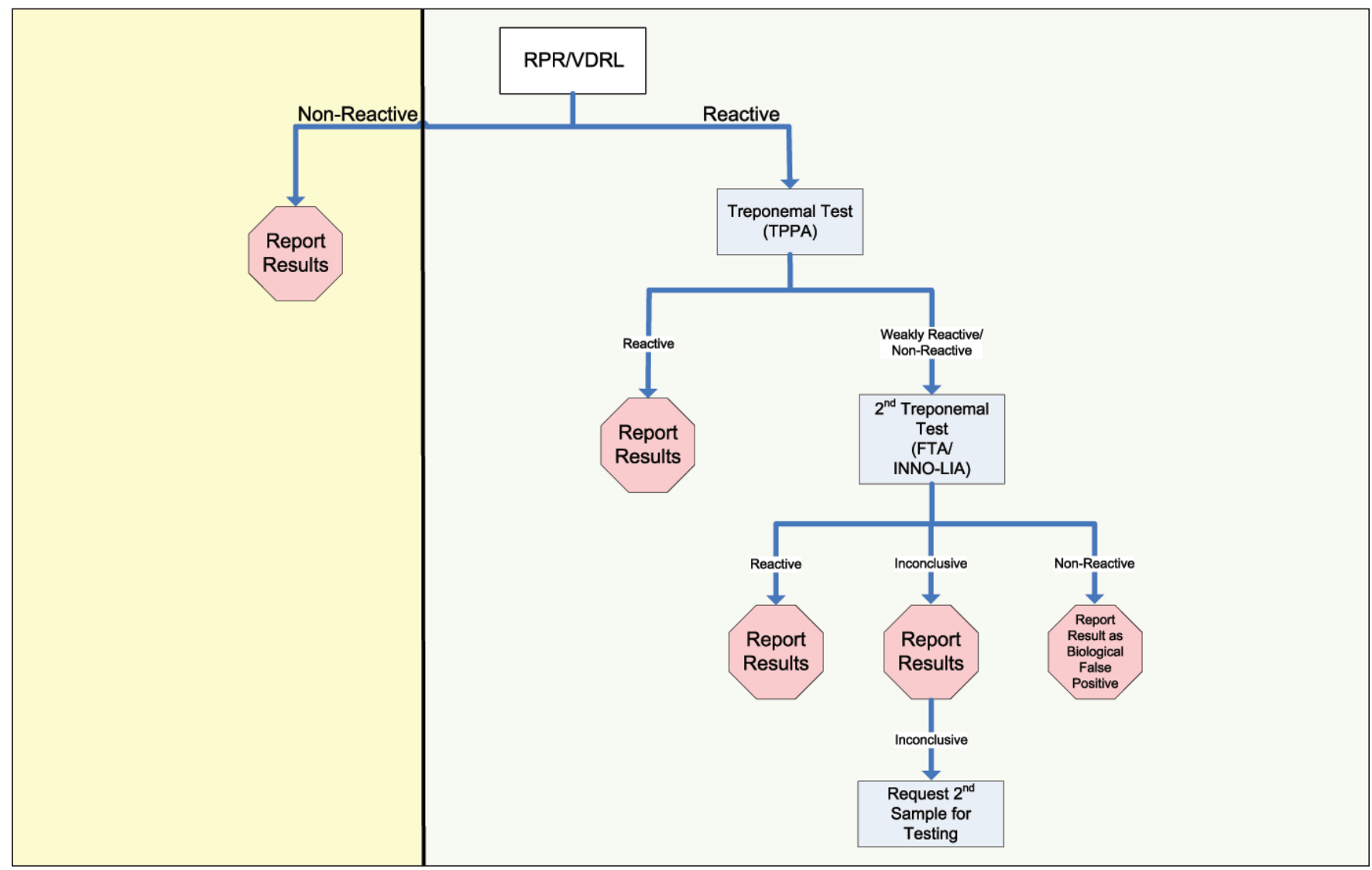

Figure 3) Traditional algorithm (non-treponemal screening)

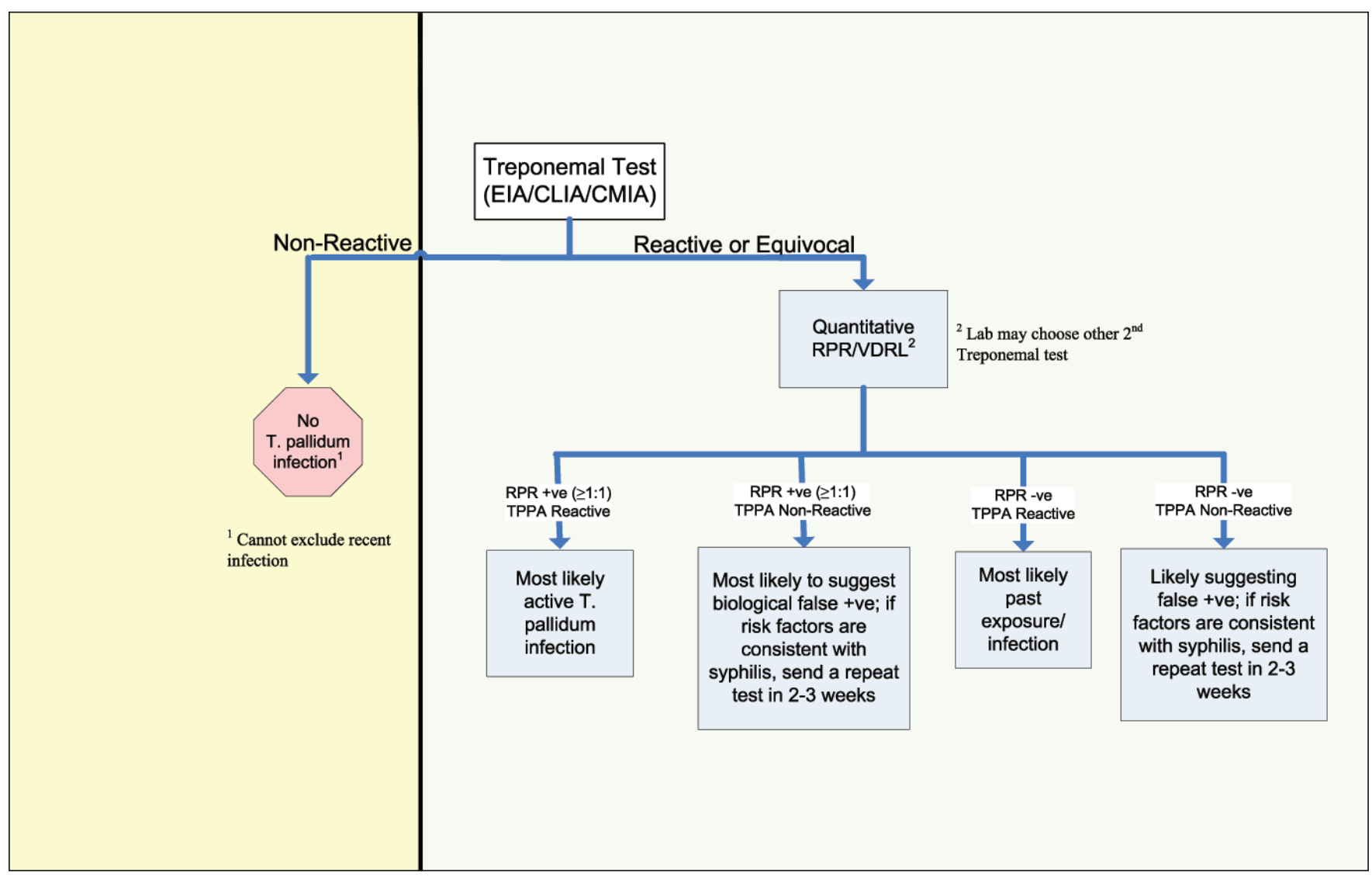

Figure 4) Reverse algorithm (treponemal screening) 
results are more likely to occur and a third treponemal test, such as INNO-LIA (Innogenetics NV, Belgium), may be needed to resolve those few cases. In addition, based on preliminary data (unpublished) from inhouse evaluations presented by some Canadian laboratories, testing algorithms may be modified using a RPR cutoff (eg, 1:8 dilutions), above which a second treponemal test may not be necessary to confirm infection with syphilis; such modifications may be made by individual laboratories based on their local evaluations until published data are available to guide recommendations for further modifications to the algorithms.

Results from all reactive serological testing should be reported promptly and concurrently to the clinician and public health department. Patients with discordant EIA/CIA and RPR/VDRL serological results and whose sera are reactive by TPPA testing are considered to have past or present syphilis; if TPPA is nonreactive, syphilis is unlikely; however, every effort should be taken to consider potential early primary or latent syphilis, especially if such result is from an individual at high risk for syphilis (Figure 4).

It is important to note that clinicians should always assess for evidence of syphilis, especially primary disease (eg, ulcerative genital, oral or anal lesions), and consider additional factors such as sexual behaviour, medical history, previous treatment history of syphilis, etc. If the clinical assessment suggests possible or probable syphilis, and the initial nontreponemal test is nonreactive (traditional algorithm), the patient should still be treated and the laboratory test should be repeated after two to four weeks. Previously untreated patients whose sera are tested with discordant EIA/CIA and RPR/VDRL results and a reactive TPPA should be treated according to Health Canada's 2010 STD Treatment Guidelines (15).

\section{RECOMMENDATIONS/SUMMARY}

Based on the current information, both the traditional or reverse algorithms are acceptable for the serological diagnosis of syphilis infection.

Each laboratory should choose the algorithm best suited to its needs, taking into consideration the laboratory's test volumes, local disease prevalence, sensitivity and specificity of the proposed assay, and available resources.

If the traditional algorithm is followed, positive non-treponemal screening test results should be confirmed by a treponemal test. If syphilis is suspected even in the absence of serological confirmation, treatment should be offered and the laboratory tests repeated after two to four weeks. If lesions are present (eg, suspect chancres), a direct test should be collected.

If the reverse algorithm is followed, and the treponemal screening test is positive, a quantitative non-treponemal test is essential to differentiate between active and past treated infection, and a second treponemal test is recommended in most situations to reduce false positivity. If the initial treponemal screening test is positive but the non-treponemal test and the second treponemal test are negative, every effort should be taken to exclude early primary or latent syphilis by repeating the test after two to four weeks before concluding that this represents a false-positive reaction.

\section{CONCLUSION}

Both traditional and reverse sequence algorithms are appropriate for the diagnosis of syphilis and decisions to use either algorithm should be based on a combination of local disease epidemiology, test volumes, performance of the proposed assays and available resources.

DISCLOSURES: The authors have no conflicts of interest to declare.

\section{TABLE 1}

Recombinant treponemal tests available in Canada, September 2014

\begin{tabular}{|c|c|c|c|c|c|c|c|}
\hline Manufacturer & $\begin{array}{l}\text { Test name } \\
\text { or platform }\end{array}$ & Test format & Specimen & $\begin{array}{l}\text { Treponemal } \\
\text { antigens included }\end{array}$ & $\begin{array}{l}\text { Antibodies } \\
\text { detected }\end{array}$ & Reference(s) & $\begin{array}{l}\text { Health } \\
\text { Canada } \\
\text { ) approved }\end{array}$ \\
\hline Abbott, USA & Architect Syphilis TP & $\begin{array}{l}\text { Two-step sandwich } \\
\text { chemiluminescent } \\
\text { microparticle assay }\end{array}$ & $\begin{array}{l}30 \mu \mathrm{L} \text { serum or } \\
\text { plasma }\end{array}$ & $\begin{array}{l}\text { TpN15, TpN17, } \\
\text { TpN47 }\end{array}$ & $\operatorname{lgG} / \lg M$ & 4 & Yes \\
\hline Biokit, Spain & Bioelisa Syphilis 3.0 & Microplate EIA & $50 \mu \mathrm{L}$ serum & P15, p17, p47 & $\lg G / \lg M$ & & Yes \\
\hline Bio-Rad, USA & BioPlex & Multiplex flow immunoassay & $5 \mu \mathrm{L}$ serum & r15kD, r17kD, r47kD & $\lg G$ & 2 & Yes \\
\hline Bio-Rad, USA & BioPlex & Multiplex flow immunoassay & $5 \mu \mathrm{L}$ serum & r17 kD, r47 kD & $\lg M$ & 2 & Yes \\
\hline $\begin{array}{l}\text { Innogenetics, } \\
\text { Belgium }\end{array}$ & INNO-LIA & Line immunoassay & $\begin{array}{l}10 \mu \mathrm{L} \text { serum } \\
\text { or plasma }\end{array}$ & $\begin{array}{l}\text { TpN15, TpN17, } \\
\text { TpN47, TmpA }\end{array}$ & $\lg G$ & 1 & No \\
\hline Diasorin, Italy & Liaison & $\begin{array}{l}\text { One-step sandwich } \\
\text { chemiluminescent assay }\end{array}$ & \multicolumn{2}{|c|}{$\begin{array}{l}70 \mu \mathrm{L} \text { serum or citrated TpN17 } \\
\text { plasma or heparinized } \\
\text { plasma }\end{array}$} & $\lg G / \lg M$ & 3,4 & Yes \\
\hline $\begin{array}{l}\text { Diesse } \\
\text { Diagnostica, Italy }\end{array}$ & Enzy-Well Syphilis IgG & Microplate EIA & $\begin{array}{l}20 \mu \mathrm{L} \text { serum or } \\
\text { plasma }\end{array}$ & $\begin{array}{l}\text { TpN15, TpN17, } \\
\text { TpN47 }\end{array}$ & $\lg G$ & & Yes \\
\hline $\begin{array}{c}\text { Euroimmun, } \\
\text { Germany }\end{array}$ & $\begin{array}{l}\text { Anti-Treponema } \\
\text { pallidum Screen } \\
\text { ELISA (IgG/lgM) }\end{array}$ & Microplate EIA & & $\begin{array}{l}\mathrm{p} 15, \mathrm{p} 17, \mathrm{p} 47 \\
\text { and TmpA }\end{array}$ & $\operatorname{lgG} / \lg M$ & & Yes \\
\hline $\begin{array}{l}\text { Euroimmun, } \\
\text { Germany }\end{array}$ & $\begin{array}{l}\text { Anti-Treponema pallidum } \\
\text { ELISA (IgG) }\end{array}$ & Microplate EIA & & $\begin{array}{l}\mathrm{p} 15, \mathrm{p} 17, \mathrm{p} 47 \\
\text { and TmpA }\end{array}$ & $\lg G$ & & Yes \\
\hline $\begin{array}{l}\text { Euroimmun, } \\
\text { Germany }\end{array}$ & $\begin{array}{l}\text { Anti-Treponema } \\
\text { pallidum Euroline- WB }\end{array}$ & Western blot & & $\mathrm{p} 15, \mathrm{p} 17, \mathrm{p} 45, \mathrm{p} 47$ & $\lg G$ & & Yes \\
\hline $\begin{array}{l}\text { Euroimmun, } \\
\text { Germany }\end{array}$ & $\begin{array}{l}\text { Anti-Treponema } \\
\text { pallidum Euroline- WB }\end{array}$ & Western blot & & $\mathrm{p} 15, \mathrm{p} 17, \mathrm{p} 45, \mathrm{p} 47$ & $\lg M$ & & Yes \\
\hline $\begin{array}{l}\text { Phoenix Airmid, } \\
\text { Canada }\end{array}$ & $\begin{array}{l}\text { TrepSure Anti-Treponema } \\
\text { EIA Screen }\end{array}$ & Microplate EIA & $\begin{array}{l}100 \mu \mathrm{L} \text { serum or } \\
\text { citrated plasma }\end{array}$ & TpN (not specified) & $\lg G / \lg M$ & 5 & Yes \\
\hline Siemens, Germany & ADVIA Centaur & $\begin{array}{l}\text { One-step chemiluminescent } \\
\text { assay }\end{array}$ & $\begin{array}{l}100 \mu \mathrm{L} \text { serum or } \\
\text { plasma (EDTA, } \\
\text { heparinized, citrate) }\end{array}$ & Tp15 and Tp17 & $\operatorname{lgG} / \lg M$ & & Yes \\
\hline Siemens, Germany & Immulite 2000 & $\begin{array}{l}\text { One-step chemiluminescent } \\
\text { assay }\end{array}$ & $\begin{array}{l}100 \mu \mathrm{L} \text { serum or } \\
\text { heparinized plasma }\end{array}$ & Tp17 & $\operatorname{lgG} / \lg M$ & & Yes \\
\hline $\begin{array}{l}\text { Trinity Biotech, } \\
\text { Ireland }\end{array}$ & Captia Syphilis TA & Microplate EIA & $\begin{array}{l}50 \mu \mathrm{L} \text { Serum or } \\
\text { plasma }\end{array}$ & $\begin{array}{l}\text { TpN15, TpN17, } \\
\text { TpN47 }\end{array}$ & $\begin{array}{l}\lg G, \lg M \\
\text { and } \lg A\end{array}$ & & Yes \\
\hline
\end{tabular}

Table references: 22,23,43-45. EIA Enzyme immunoassay; Ig Immunoglobulin 


\section{REFERENCES}

1. Augenbraun M, French A, Glesby M, et al. Hepatitis C virus infection and biological false-positive syphilis tests. Sex Transm Infect 2010;86:97-98.

2. Portnoy J, Brewer JH, Harris A. Rapid plasma reagin test for syphilis. Public Health Rep 1957;72:761-6.

3. Normansell, D. 2002. Specimen collection and handling. In: Rose NR, Hamilton RG, Betrick B, eds. Manual of Clincal and Laboratory Immunology, 6th edition. Washington, DC: ASM Press.

4. Johnson R, Kraus SJ, Larsen SA. 1998. Collection of Blood and Cerebrospinal Fluid. p. 6 in Manual of Syphilis Tests.

5. Pope V, Norris SJ, Johnson RE. 2007. Treponema and other human host-associated spirochetes. p. 987-1003. In: Murray PR, Baron EJ, Jorgensen JH, Landry ML, Pfaller MA, eds. Manual of Clinical Microbiology, 9th edn, vol. 1. Washington, DC: ASM Press

6. Larsen SA, Steiner BM, Rudolph AH. Laboratory diagnosis and interpretation of tests for syphilis. Clin Microbiol Rev 1995;8:1-21.

7. Catterall RD. Systemic disease and the biological false positive reaction. Br J Vener Dis 1972;48:1-12.

8. Harris A, Rosenberg AA, Riedel LM. A microflocculation test for syphilis using cardiolipin antigen; preliminary report. J Vener Dis Inf 1946;27:169-74.

9. Portnoy J, Bossak HN, Falcone VH, Harris A. Rapid reagin test with unheated serum and new improved antigen suspension. Public Health Rep 1961;76:933-5.

10. Falcone VH, Stout GW, Moore MB. Evaluation of rapid plasma reagin (circle) card test. Public Health Rep1964;79:491-5.

11. Pettit DE, Larsen SA, Harbec PS, et al. Toluidine red unheated serum test, a nontreponemal test for syphilis. J Clin Microbiol 1983;18:1141-5.

12. Wende RD, Mudd RL, Knox JM, Holder WR. The VDRL slide test in 322 cases of darkfield positive primary syphilis. South Med J 1971;64:633-4.

13. Geisler WM. The prozone phenomenon in syphilis testing. South Med J 2004;97:327-8.

14. McMillan A, Young H. Reactivity in the Venereal Diseases Research Laboratory test and the Mercia IgM enzyme immunoassay after treatment of early syphilis. Int J STD AIDS 2008;19:689-93.

15. Canadian Guidelines on Sexually Transmitted Infections, 2008 edn. Ottawa: Public Health Agency of Canada. Updated January 2010.

16. Nandwani R, Evans DT. Are you sure it's syphilis? A review of false positive serology. Int J STD AIDS 1995;6:241-8.

17. Ratnam, S. 2005. The laboratory diagnosis of syphilis. Can J Infect Dis Med Microbiol 16:45-51.

18. Garson W. The treponemal tests for syphilis. South Med J 1957;50:911-8.

19. Hunter EF. The fluorescent treponemal antibody-absorption (FTA-ABS) test for syphilis. CRC Crit Rev Clin Lab Sci 1975;5:315-30.

20. Hunter EF, Deacon WE, Meyer PE. An improved FTA test for syphilis, the absorption procedure (FTA-ABS). Public Health Rep 1964;79:410-2.

21. Binnicker MJ, Jespersen DJ, Rollins LO. Treponemal-specific tests for the serodiagnosis of syphilis: A comparative evaluation of seven assays. J Clin Microbiol 2011;49:1313-7.

22. Gomez E, Jespersen DJ, Harring JA, Binnicker MJ. Evaluation of the Bio-Rad BioPlex 2200 syphilis multiplex flow immunoassay for the detection of IgM- and IgG-class antitreponemal antibodies. Clin Vaccine Immunol 2010;17:966-8.

23. Wong EH, Klausner JD, Caguin-Grygiel G, et al. Evaluation of an IgM/IgG sensitive enzyme immunoassay and the utility of index values for the screening of syphilis infection in a high-risk population. Sex Transm Dis 2011;38:528-32.
24. Hagedorn HJ, Kraminer-Hagedorn A, De Bosschere K, Hulstaert F, Pottel H, Zrein M. Evaluation of INNO-LIA Syphilis Assay as a confirmatory test for syphilis. J Clin Microbiol 2002;40:973-8.

25. Lam TK, Lau HY, Lee YP, Fung SM, Leung WL, Kam KM. Comparative evaluation of the INNO-LIA syphilis score and the MarDx Treponema pallidum immunoglobulin G Marblot test assays for the serological diagnosis of syphilis. Int J STD AIDS 2010;21:110-3.

26. Sambri V, Marangoni S, Eyer C, et al. Western immunoblotting with five Treponema pallidum recombinant antigens for serologic diagnosis of syphilis. Clin Diagn Lab Immunol 2001;8:534-49.

27. Young H, Moyes A, McMillan A, Patterson J. Enzyme immunoassay for anti-treponemal IgG: Screening or confirmatory test? J Clin Pathol 1992;45:37-41.

28. Samoff E, Koumans EH, Gibson JJ, Ross M, Markowitz LE. Pre-treatment syphilis titers: Distribution and evaluation of their use to distinguish early from late latent syphilis and to prioritize contact investigations. Sex Transm Dis 2009;36:789-93.

29. French P, Gomberg M, Janier M, Schmidt B, van Voorst Vader P, Young H. IUSTI: 2008 European Guidelines on the Management of Syphilis. Int J STD AIDS 2009;20:300-9.

30. Mishra S, Boily MC, Ng V, et al. The laboratory impact of changing syphilis screening from the rapid-plasma reagin to a treponemal enzyme immunoassay: A case-study from the Greater Toronto Area. Sex Transm Dis 2010;38:190-6.

31. Woznicová V, Valisová Z. Performance of CAPTIA SelectSyph-G enzyme-linked immunosorbent assay in syphilis testing of a highrisk population: Analysis of discordant results. J Clin Microbiol 2007;45:1794-7.

32. Centers for Disease Control and Prevention. Discordant results from reverse sequence syphilis screening - five laboratories, United States, 2006-2010. MMWR Morb Mortal Wkly Rep 2011;60:133-7.

33. Zhang W, Yen-Lieberman B, Means C, Kreller R, Waletzky J, Daly TM. The impact of analytical sensitivity on screening algorithms for syphilis. Clin Chem 2012;58:1065-6.

34. Peterman T, Schillinger J, Blank S, et al. Syphilis testing algorithms using treponemal tests for initial screening - four laboratories, New York City, 2005-2006. MMWR Morb Mortal Wkly Rep 2008;57:872-5.

35. Binnicker MJ, Jespersen DJ, Rollins LO. Direct comparison of the traditional and reverse syphilis screening algorithms in a population with a low prevalence of syphilis. J Clin Microbiol 2012;50:148-50;

36. Hunter MG, Robertson PW, Post JJ. 2012. Significance of isolated treponemal chemiluminescence immunoassay results. J Infect Dis 2013;207:1416-23.

37. Owusu-Edusei K Jr, Koski KA, Ballard RC. The tale of two serologic tests to screen for syphilis - treponemal and nontreponemal: Does the order matter? Sex Transm Dis 2011;38:448-56.

38. Gratrix J, Plitt S, Lee BE, et al. Impact of reverse sequence syphilis screening on new diagnoses of late latent syphilis in Edmonton, Canada. Sex Transm Dis 2012;39:528-30

39. Tong ML, Lin LR, Liu LL, et al. Analysis of 3 algorithms for syphilis serodiagnosis and implications for clinical management. Clin Infect Dis 2014;58:1116-24

40. Chuck A, Ohinmaa A, Tilley P, Singh A, Jacobs P. Cost effectiveness of enzyme immunoassay and immunoblot testing for the diagnosis of syphilis. Int J STD AIDS 2008;19:393-9.

41. Tsang RSW, Radons SM, Morshed M; the Syphilis Laboratory Task Group of the Canadian Public Health Laboratory Network. Laboratory diagnosis of syphilis: A survey to examine the range of tests used in Canada. Can J Infect Dis Med Microbiol 2011;22:83-7.

42. Dumaresq J, Langevin S, Gagnon S, et al. Clinical prediction and diagnosis of neurosyphilis in HIV-infected patients with early syphilis. J Clin Microbiol 2013;51:4060-6. 


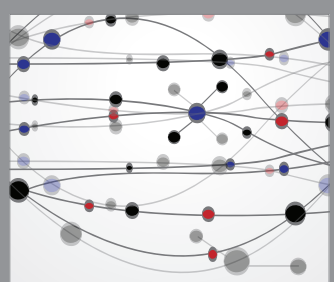

The Scientific World Journal
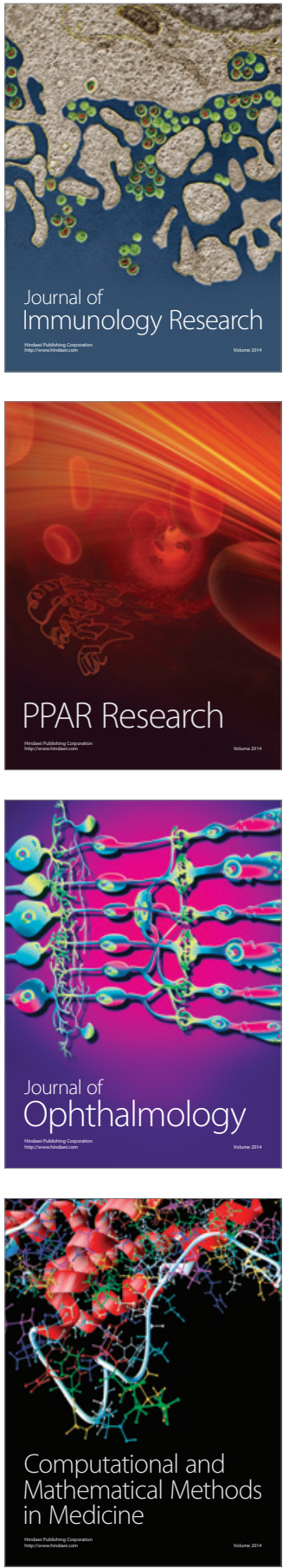

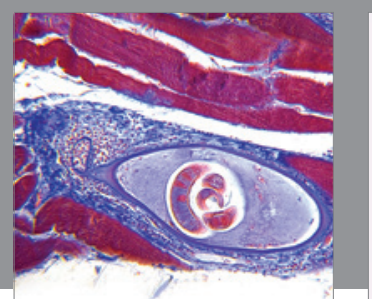

Gastroenterology Research and Practice

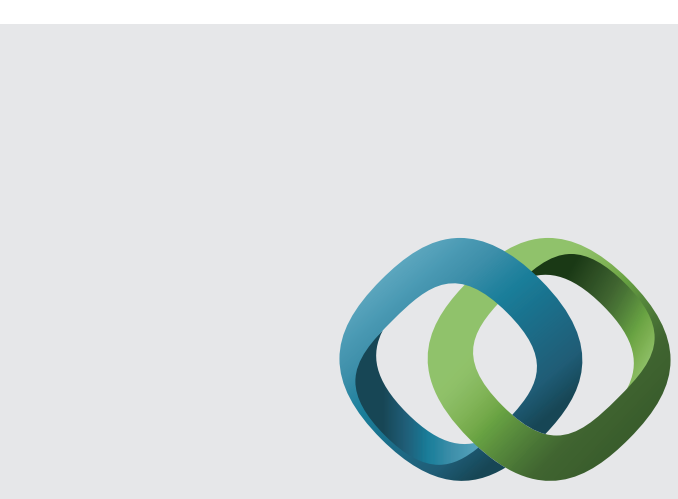

\section{Hindawi}

Submit your manuscripts at

http://www.hindawi.com
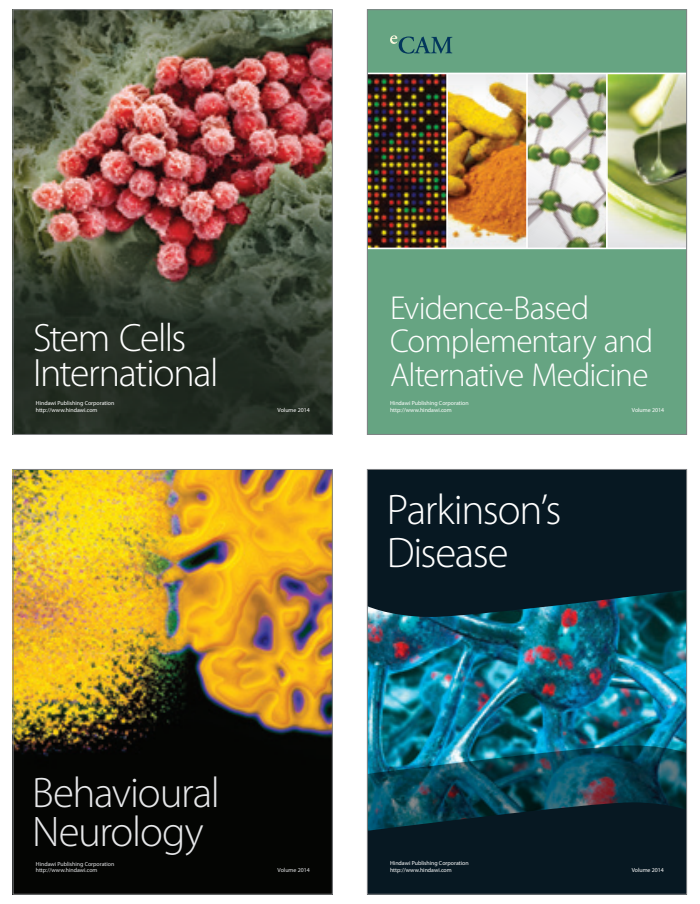
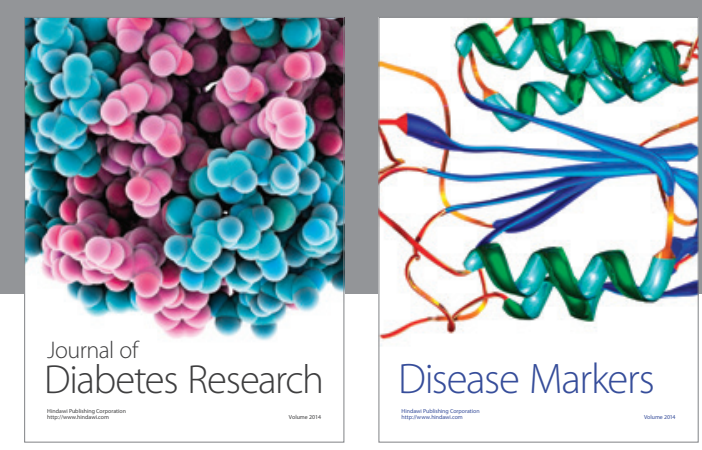

Disease Markers
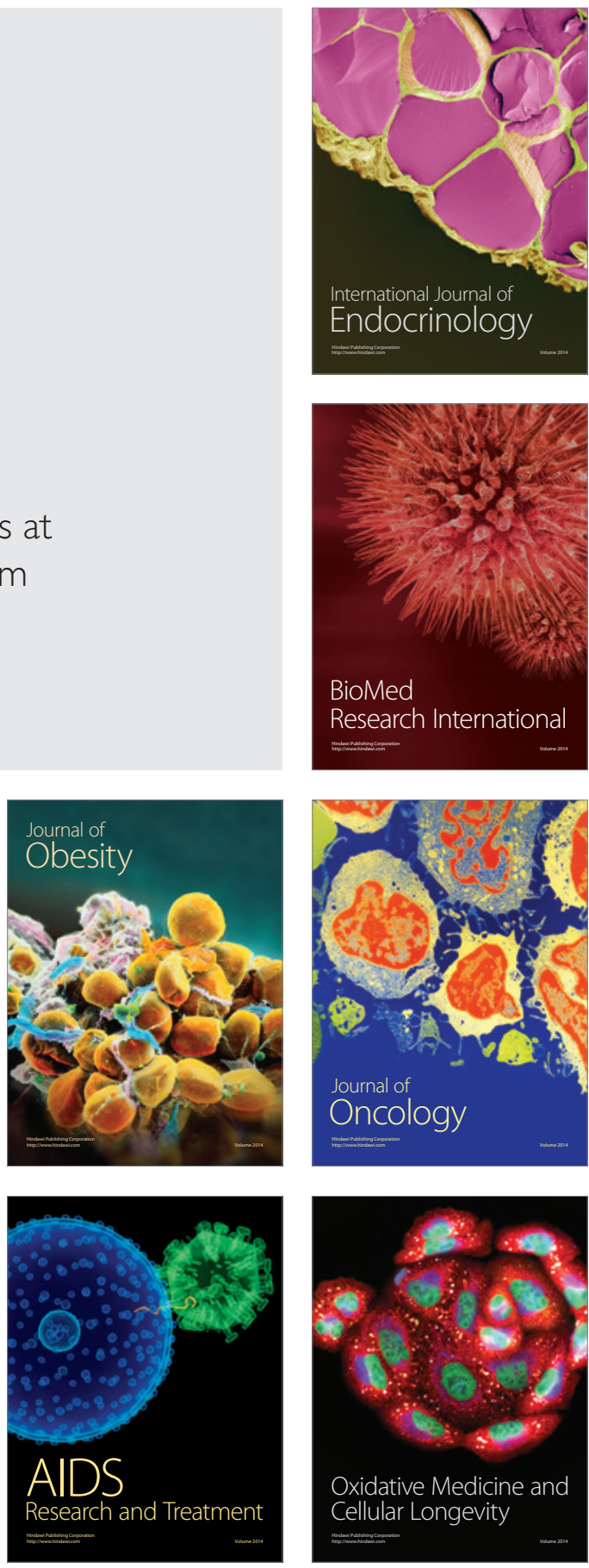